European Research Studies,

Volume 7, Issue (1-2) 2004

\title{
Impact of EU- FDI on Economic Growth in Middle Eastern Countries
}

\section{By}

M.M. Metwally*

\begin{abstract}
:
This paper develops a simultaneous equations model to test the process of interaction between foreign direct investment, exports and economic growth in three Middle Eastern countries: Egypt, Jordan, Oman, and test for any possible feedback effects. Most of the FDI in these countries flows from the EU. The simultaneous equations model results suggest that higher rates of economic growth result in a greater inflow of foreign capital. The regression results also suggest that interest rate differentials exert a much stronger effect than economic growth on the attraction of foreign capital in the case of Egypt. However, this variable does not seem to play a significant role in the case of Oman. Moreover, the simultaneous equations model results suggest that there is a feedback effect in the relationship between economic growth and capital inflow in all sample countries. A greater inflow of foreign capital leads to growth in the exports of good and services. The expansion in exports leads to growth in GNP, which in turn, encourages the attraction of more foreign capital.
\end{abstract}

\footnotetext{
* Professor Mokhtar M. Metwally is QNB Chair of Economics and the Dean of the College of Business and Economics, University of Qatar. He can be contacted at P.O. Box 2713, Doha, Qatar. Tel (974) 4852823, Fax (974) 4832923, e-mail: metwally@qu.edu.qa. This study is part of a major research project conducted by the National Research at Center at the University of Qatar. The Qatar National Bank (QNB) financially sponsors this Center.
} 


\section{Introduction}

Most Middle Eastern governments have recently decided to encourage the role of the private sector through vigorous programs of privatization and the implementation of microeconomic policies that minimize price distortions in goods and factor markets, largely by opening the economy to international trade and encouraging competitiveness.

Egypt, Jordan and Oman are a few Middle Eastern economies that have decided to benefit from foreign direct investment in their struggle to achieve sustained economic growth. The three economies, however, do differ substantially in size, structure and stage of development. Oman, the smallest (with a population of less than 2.6 millions), is an oil-producer (but not a member of OPEC) with the highest per capita income (almost US\$7000). Egypt is the largest (over 65 million population), most industrialized but with least per capita income (less than US\$1300). The population of Jordan is approximately 6.5 millions and its per capita income is slightly higher than that of Egypt.

All three sample countries have introduced a number of measures which aim at attracting foreign capital at a large scale. The measures introduced by Egypt, for instance, include the abolishment of export taxes, foreign exchange controls and bureaucratic procedures in the way of investment. One of the main goals of the Egyptian government is to address the deficit in the country's balance of trade. Egypt is one of the few developing countries that suffer from a persistent deficit in its trade balance (Metwally and Tamaschke, 1995). Imports of goods exceeded exports of goods each year during the past three decades. Both the Jordanian and Oman governments have been introducing for a long time a number of incentives to attract the foreign investor. These economies are hoping to use foreign capital, and the accompanied know-how in expanding the role of the export sector in order to enhance their international competitiveness and improve the performance of their balance of payment. This is particularly so for the Oman economy following the downfall in oil prices in 1986.

As a result of the above measures, the conditions conducive to economic growth have improved dramatically in the three Middle-Eastern economies. Available statistics (IMF: International Financial Statistics, 2001) reveal some of the following most noticeable changes:

1. A great enhancement in international liquidity. The value of total reserves minus gold in Egypt increased from US\$688m at the end of 1981 to US\$13118m at the end of 2000 . The comparable figures were US $\$ 1087 \mathrm{~m}$ in 1981 and US $\$ 3331 \mathrm{~m}$ in 2000 for Jordan and US\$581m in 1981 and US\$2380m in 2000 for Oman.

2. A relative stability in the exchange rate The strength in international liquidity has resulted in a relative stability in the rate of exchange of the national currency to the US dollar. Only one exchange rate has been in force in Egypt since 1991. This rate went up from 3.3322 Egyptian Pounds per one US Dollar in 
1991 to only 3.690 Egyptian Pounds per one US Dollar in 2000. However, recent months have witnessed a significant deterioration in the value of the Egyptian Pound (It stands currently at approximately 5.25 Egyptian Pounds per 1 US\$). This may be due to the increasing deficit in the balance of trade and narrowing the gap in the interest rate differentials. A similar pattern appears to hold for the Jordanian Dinar. The rate of exchange went down from 1.4689 US Dollar per one Jordanian Dinar in 1991 to only 1.4104 US Dollar per one Jordanian Dinar in 2000. Oman, on the other hand pegged it Riyal to the US Dollar. The Omani Riyal per US Dollar went down from .3454 Riyals in 1981 to only .3845 Riyals in 2000.

3. Greater inflow of foreign capital and transfers. The stability in the rate of exchange combined with the significant differentials between real domestic interest rates and international rates resulted in a significant inflow of foreign capital.

4. An Improvement in the balance of current accounts. The substantial increase in direct foreign investment had a noticeable favourable impact on the balances of current account of the receiving countries. The Jordanian current account turned from a continuous deficit in 1981 to a surplus since 1997. Egypt, experienced a surplus on its current account, for the first time, during the period 1990-95.

The aim of this paper is to examine the impact of foreign capital inflow on economic growth in Egypt. Jordan and Oman. The paper is divided into four sections. Section 1 briefly review the Impact of EU-MEC Partnership on EU-FDI to the Middle East Section 2 develops a simultaneous equations model to test the process of interaction between foreign capital inflow, economic growth, and exports and test for any possible feedback effects. Section 3 reports the regression results of the simultaneous equations model. The main conclusions of the paper are summarized in section four.

\section{Impact of EU-MEC Partnership on EU-FDI to the Middle East}

The European Union's position as the world's most important source of FDI was reconfirmed in 1999 as outflows of FDI rose for the sixth consecutive year. The United Kingdom, which alone accounted for 39 per cent of total European Union outflows, was followed by two other large economies, France and Germany, and by the Netherlands.

The historical relationship and the geographical location between the EU countries and the Middle Eastern (ME) countries had an effect on their economic relationship in general and their trade situation in particular. The EU countries are considered to be the main trading partners of the ME countries. Acknowledgment of these historical, geographical and economic ties was materialized as far as 1977 
when Jordan, Syria, Lebanon and Egypt signed bilateral trade protocols with the $\mathrm{EU}$

The evolution of EU FDI (Foreign Direct Investment) during the 1990s shows an increasing importance of the Mediterranean region for EU investors. EU assets in the MPC (excluding Cyprus and Malta) rose by an average annual rate of 19 per cent between 1994 and 1999, reaching 14 bn euro at the end of the period. Over the same period total EU assets held in other countries grew on average by 22 per cent per year. The major increase in EU FDI in the MPC began in 1998 and pushed by sizeable investments in Turkey and Egypt - reached record levels in 2000 (Balzan, 2001).

Egypt has been a major beneficiary of EU financial co-operation. The framework of co-operation with Egypt is divided into two periods. The first period (1977-1995) was covered by a series of four bilateral protocols and several activities are still continuing. The second period (from 1996) is covered by the MEDA programme.

The principal actions currently funded by bilateral EU-Egypt protocols and funds are:

- Public Enterprise Reform and Privatization Programme (EUR 43 million)

- Private Sector Development Programme (EUR 25 million + EUR 20 million)

- Reform of the Financial Sector/Central Bank (EUR 11.7 million)

- Private Sector Financial Scheme (non-protocol. 330 million EGP = EUR 52.5 million)

- Social Fund for Development -Phase I (non-protocol. 776 million $\mathrm{EGP}=122.5$ million)

- Support to the Population Programme in Upper Egypt (EUR 10 million)

The following major programmes funded under the substantially increased MEDA budgets are:

- Social Fund for Development - Phase II (EUR 155 million, in collaboration with the World Bank)

- Basic Education Programme (EUR 100 million, in collaboration with the World Bank)

- Industrial Modernization Programme (EUR 250 million)

- Health Sector Programme (EUR 110 million)

The programming of new actions to be funded under MEDA for the period 2002-2004 has already begun. The priorities will be to support the implementation of the EU-Egypt Association Agreement and to maintain the balance between economic and social development. 
The long negotiations for a new EU-Egypt Association Agreement were effectively concluded in June 1999 when both parties closed all outstanding positions. The agreement was signed on 25 June 2001 in Luxembourg and will come into force when it has been ratified by the Egyptian, the European, and Member State Parliaments. This agreement heralds a new phase in relations with Egypt and will mark an important milestone in the creation of the EuroMediterranean Partnership.

The EU signed an Association Agreement with Jordan on Nov 24, 1997, was ratified by the Jordanian Parliament in September 1999 and came into force on May 1,2002 after being ratified by all the $15 \mathrm{EU}$ countries. The signing of this agreement came in light of the government's commitment towards trade liberalization that was accelerated since the mid 90s. The agreement revolves around three major themes; political, economic and financial, and social and cultural.

Apart from the strategic importance of the Gulf region, the GCC remains the EU's sixth largest export market. Furthermore the EU consistently has an export surplus in the trade balance with the GCC. In 2000, the EU exports revenue from the GCC amounted to 29 billion euro whereas imports amounted to 22 billion euro. Crude oil represents almost two thirds of EU imports from the GCC.

The EU exports to GCC are diversified, but the main weight remains on large machinery such as power generation plants, railway locomotives and aircrafts, electrical machinery items and mechanical appliances. These product groups make up about one third of the total exports. Medicaments and medical equipment make up another large part, leaving the remaining exports to a wide variety of products.

The latest statistics on investments show a drastic decline in the EU investments in the Gulf region. The EC investments have halved from the 3 billion EURO in 1999 to 1.5 billion in 2000. At the same time the GCC investments increased by more than 15\% from about 4 billion EURO in 1999 to about 4.6 billion in 2000 .

\section{A Simultaneous Equation Model}

The relationship between foreign capital inflow and economic growth in developing countries is not a one-way relationship. Direct private investment does not only affect economic growth but is also affected by it. Economies that enjoy relatively higher rates of growth succeed in attracting foreign investment. On the other hand, foreign investment contributes to the acceleration of economic growth for a number of reasons:

1. Most developing countries lack capital as a factor input. The inflow of foreign capital results in an expansion of the productive capacity of the economy. This contributes towards economic growth.

2. Capital inflows at substantial rates will reduce the need for borrowing. This will reduce the debt-service ratio, which can be a real drain on heavily-indebted countries, such as Egypt (Jaber, 1986). The high debt-service ratio deprives the 
economy of the direct and indirect benefits of a large percentage of exports. This reduces the ability of its economy to grow and increases its dependence on foreign debt (Metwally and Tamaschke, 1994). Thus, by reducing the debt-service ratio, foreign investment contributes indirectly to economic growth.

3. Direct foreign investment is usually accompanied by know-how, up-to-date technology and managerial skills that are essential for economic growth but lacked by most developing countries.

4. Direct foreign investment usually assists in the expansion and creation of new markets. This enhances the country's ability to export and contributes to economic growth.

5. By expanding the export revenue, capital inflow plays a major role in alleviating the debt-service problem in Egypt. The need to borrow will be reduced and the growth will be accelerated if direct foreign investment flows at substantial rates.

It follows from the above that the impact of capital inflow on the process of economic growth, should be examined by a simultaneous-equations model to take an explicit account of the mentioned process of interaction and capture any possible feedback effects

The following simultaneous relationships, known as structural equations, have been developed:

Structural Equations:

$$
\begin{aligned}
& \mathrm{K}_{\text {it }}=\mathrm{a}_{\mathrm{o}}+\mathrm{a}_{1} \mathrm{y}_{\text {it }}+\mathrm{a}_{2} \mathrm{r}_{\text {it }}+\mathrm{u}_{1 \mathrm{t}} \\
& \mathrm{y}_{\text {it }}=\mathrm{b}_{0}+\mathrm{b}_{1} \mathrm{x}_{\text {it }}+\mathrm{b}_{2} \mathrm{~A}_{\text {it }}+\mathrm{u}_{2 t} \\
& \mathrm{x}_{\text {it }}=\mathrm{c}_{0}+\mathrm{c}_{1} \mathrm{w}_{\mathrm{it}}+\mathrm{c}_{2} \mathrm{~K}_{\text {it }}+\mathrm{u}_{3 \mathrm{t}}
\end{aligned}
$$

\section{Endogenous Variables:}

$\mathrm{K}_{\text {it }}=$ Foreign direct investment in the ith economy in period $\mathrm{t}$

$\mathrm{y}_{\text {it }} \quad=$ Rate of growth of GNP of the ith economy in period $\mathrm{t}$

$\mathrm{x}_{\text {it }}=$ Rate of growth of exports of goods and services of the ith economy in

period $t$

\section{Predetermined Variables:}

$\mathrm{r}_{\text {it }}=$ Real interest rate differential in the ith economy, i.e. the difference 
period $t$.

between (real) domestic interest rates and international rates in

$\mathrm{A}_{\mathrm{it}}=$ Rate of growth of domestic absorption in the ith economy in period $\mathrm{t}$

$\mathrm{w}_{\text {it }} \quad=$ Rate of growth of major trading partners of the ith economy in period $\mathrm{t}$

The first equation shows that the inflow of equity capital will be determined by economic growth and interest rate differentials. Countries that enjoy higher growth rates and offer higher rates of return on invested capital are expected to attract more equity capital. Therefore, both the coefficients of this equation are expected to carry a positive sign.

The second equation in the system assumes that economic growth depends on growth in exports of goods and services and domestic absorption. Thus both the coefficients $\left(b_{1}\right)$ and $\left(b_{2}\right)$ are expected to carry a positive sign. However, it should be noted that the extent of the impact of the rate of growth in domestic absorption will depend on leakage to imports (Edwards, 1991).

The third equation tests the hypothesis that exports of goods and services are determined by the forces of demand for and supply of exports. Demand is assumed to depend on income growth in major trading partners and the opening of new markets. Foreign capital can perform a dual role. First, it provides a factor input and hence increases the capacity of the export industry. Secondly, foreign capital assists domestic industries to penetrate foreign markets. Thus the two coefficients, $\left(\mathrm{c}_{1}\right)$ and $\left(\mathrm{c}_{2}\right)$ are expected to carry a positive sign.

The above system is mathematically complete in the sense that it contains as many equations as it contains endogenous variables. Applying the order and rank conditions of identification to our simultaneous equations model, we notice that each equation is over-identified (Greene, 2000). Hence, the method of two-stage least squares is appropriate to estimate the equations of the model (Mittelhammer et al, 2000).

\section{Regression Results}

The above model was tested for the period 1981-2000. Data were extracted from the IMF International Financial Statistics 2001 Yearbook, the International Bank 2001 World Tables, various issues of Economic Bulletins and the Statistical Abstracts of sample countries.

The data were used in 1990 constant prices with allowances for the real income effects of changes in the terms of trade; on this see Metwally and Tamaschke (1980), and Mukherjee et al (1998). 
An important step before estimating the model is to determine the time series properties of the data. This is an important issue since the use of nonstationary data can result in spurious regression results. To this end, the ADF test has been adopted to examine the stationarity, or otherwise, of the time series data. The empirical results of the Augmented Dickey-Fuller (ADF, 1979, 1981) test have not been reported here but are available from the author upon request. According to the ADF test results, all the variables employed in the three equations are I(1). Since only 20 annual observations are used in the estimation process (1981-2000), the unit root test results should be taken with great cautious, as all these tests are appropriate for large samples.

The regression results are given in Table 1 for Egypt, Jordan and Oman respectively. As the nature of the sampling distribution of 2SLS estimates in small samples is unknown (Maddala, 2000), the equations were also estimated individually by ordinary least squares (OLS). These (biased) OLS estimates have finite small sample variances (Greene, 2000).

The regression results suggest that the model is a good fit as indicated by the values of (adjusted) $\mathrm{R}^{2}$ and $\mathrm{F}$ statistics. Also, the estimated D-W statistic suggests that there is no serious problem of serial correlation. Moreover, inspection of the residuals about the estimated equations suggests that there is no undue cause for concern about the homogeneity of the distribution of the residuals. It must be emphasized, however, that the various test statistics are given for what they are worth since their precise meaning in small sample simultaneous models is arguable (Davidson 2000). The OLS results strongly support the kind of conclusions following from the 2SLS results.

The regression results of Table 1 would seem to suggest that:

1. The coefficients of the variable representing economic growth in the first equation, is positive and statistically significant in all three countries. This suggests that a higher rate of economic growth results in greater inflow of foreign private investment. The regression results also suggest that interest rate differentials exert a significant effect on the attraction of foreign direct investment in both Egypt and Jordan but not in Oman. These results suggest that interest rate differentials have a much stronger effect on the attraction of foreign capital than economic growth in the case of Egypt.

2. Equation 2 results suggest that real growth in economic absorption has a strong positive effect on economic growth in all three-sample countries. The coefficient of the variable A is positive and statistically significant. The results of this equation also support the hypothesis that economic growth is directly and strongly affected by growth in exports of goods and services. The coefficient of the variable $\mathrm{x}$, which represents export growth, is positive and statistically significant in all cases.

3. The regression results of the third equation suggest that growth in the economies of the major trading partners exert a strong positive influence on the country's exports of goods and services. These results suggest that growth in the economies of the major trading partners has a much stronger effect on the 
attraction of direct foreign investment in the case of Oman. This may be explained by the fact that most foreign direct investment that flows into Oman comes from neighbouring GCC oil-producers whose economies experience significant fluctuations in their growth due to fluctuations in oil prices.

4. The results of the third equation also support the hypothesis that exports of goods and services are strongly influenced by the inflow of foreign equity capital that contributes to investment in the export sector and creates new foreign markets for the domestic products. The coefficient of the variable $\mathrm{K}$ is positive and statistically significant in all sample-countries.

5. The regression results of the simultaneous equations model suggest that there is a feedback effect in the relationship between economic growth and capital inflow. A greater inflow of foreign capital leads to growth in the exports of good and services. The expansion in exports leads to growth in GNP, which in turn, encourages the attraction of more foreign capital.

Table 1

Regression Results of the Simultaneous Equations Model:

$$
\begin{aligned}
& \text { 1. Egypt } \\
& \mathrm{K}_{\mathrm{t}}=-1765.4+164.5 \mathrm{y}_{\mathrm{t}}+812.9 \mathrm{r}_{\mathrm{t}} \\
& (-7.665) \quad(5.413) \quad \text { (18.7) } \\
& \mathrm{R}^{-2}=.958 \quad \mathrm{~F}=151.3 \quad \mathrm{DW}=1.899 \\
& \mathrm{y}_{\mathrm{t}}=1.603+.481 \mathrm{x}_{\mathrm{t}}+.159 \mathrm{~d}_{\mathrm{t}} \\
& \text { (1.988) (3.226) (3.603) } \\
& \mathrm{R}^{-2}=.877 \quad \mathrm{~F}=43.9 \quad \mathrm{DW}=1.879 \\
& \mathrm{x}_{\mathrm{t}}=-.382+1.462 \mathrm{w}_{\mathrm{t}}+.00061 \mathrm{~K}_{\mathrm{t}}
\end{aligned}
$$

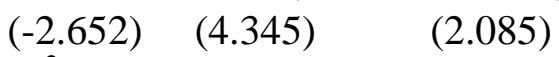

$$
\begin{aligned}
& \mathrm{R}^{-2}=.747 \quad \mathrm{~F}=20.1 \quad \mathrm{DW}=1.744
\end{aligned}
$$

\section{Jordan}

$$
\begin{aligned}
\mathrm{K}_{\mathrm{t}}= & \begin{array}{l}
-77.2 \\
(-3.476)
\end{array} \quad+83.0 \mathrm{y}_{\mathrm{t}}+17.1 \mathrm{r}_{\mathrm{t}} \\
& \mathrm{R}^{-2}=.879 \quad \mathrm{~F}=66.3 \quad \mathrm{DW}=3.145 \\
\mathrm{y}_{\mathrm{t}}= & .066+.543 \mathrm{x}_{\mathrm{t}}+.162 \mathrm{~A}_{\mathrm{t}} \\
& \begin{array}{l}
.483) \quad(4.710) \quad(2.455) \\
\\
\mathrm{R}^{-2}=.919 \quad \mathrm{~F}=114.3 \quad \mathrm{DW}=1.615
\end{array}
\end{aligned}
$$




$$
\begin{aligned}
\mathrm{x}_{\mathrm{t}}= & \begin{array}{l}
1.435+1.072 \mathrm{w}_{\mathrm{t}}+.0229 \mathrm{~K}_{\mathrm{t}} \\
(6.925) \quad(3.433) \quad(7.112)
\end{array} \\
& \mathrm{R}^{-2}=.950 \quad \mathrm{~F}=180.0 \quad \mathrm{DW}=2.307
\end{aligned}
$$

\section{Oman}

$$
\begin{aligned}
& \mathrm{K}_{\mathrm{t}}=\underset{(-3.663)}{-70.1}+\underset{(4.010)}{38.787} \mathrm{y}_{\mathrm{t}}+14.365 \mathrm{r}_{\mathrm{t}} \\
& \mathrm{R}^{-2}=.814 \quad \mathrm{~F}=44.8 \quad \mathrm{DW}=1.795 \\
& \mathrm{y}_{\mathrm{t}}=1.596+.288 \mathrm{x}_{\mathrm{t}}+.387 \mathrm{~d}_{\mathrm{t}} \\
& \text { (6.659) (3.587) (2.306) } \\
& \mathrm{R}^{-2}=.830 \quad \mathrm{~F}=47.7 \quad \mathrm{DW}=1.482 \\
& \mathrm{x}_{\mathrm{t}}=.492+2.420 \mathrm{~W}_{\mathrm{t}}+.0088 \mathrm{~K}_{\mathrm{t}} \\
& \begin{array}{lll}
(1.387) \quad(7.531) \quad(2.256)
\end{array} \\
& \mathrm{R}^{-2}=.895 \quad \mathrm{~F}=81.6 \quad \mathrm{DW}=1.670
\end{aligned}
$$

* The figures in the parentheses under the coefficients are $t$ values

\section{Conclusions}

The main findings of this report may be summarized in the following:

1. The implementation of microeconomic policies that minimize price distortions in goods and factor markets and open the economy to international trade and encourage competition have resulted in conditions conducive to economic growth in sample countries. These countries have been enjoying a great enhancement in international liquidity, a relative stability in the exchange rate, a greater inflow of foreign capital and an improvement in the balance of current accounts.

2. A simultaneous-equations model that takes an explicit account of the process of interaction and captures any possible feedback effects is appropriate to examine the impact of foreign direct investment on the process of economic growth.

3. The simultaneous equations model results suggest that the higher rate of economic growth of the sample countries resulted in a greater inflow of foreign direct investment. The regression results also suggest that interest rate differentials exerted a much stronger effect on the attraction of foreign capital than economic growth in the case of Egypt. It is, therefore, in the best interest of the Egyptian economy that this differential is maintained not only to attract foreign capital but also to encourage domestic savings and maintain the stability of the exchange rate. Thanks to these differentials, most earning transfers of Egyptians working abroad have been attracted to "investment certificates" and other forms of investment in local currency to benefit from the high interest rates.

4. The results of the simultaneous equations model support the hypothesis that economic growth is directly and strongly affected by growth in exports of goods 
and services and growth in domestic absorption. However, the leakage to imports weakens the impact of growth in domestic absorption on economic growth.

5. The regression results support the hypothesis that exports of goods and services are strongly influenced by the inflow of foreign capital, which contributes to investment in the export sector and creates new foreign markets for the domestic products. Hence, a greater inflow of direct foreign investment is likely to contribute towards improving the current account.

6. The regression results of the simultaneous equations model suggest that there is a feedback effect in the relationship between economic growth and capital inflow. A greater inflow of foreign capital leads to growth in the exports of good and services. The expansion in exports leads to growth in GNP, which, in turn, encourages the attraction of more foreign capital.

\section{References}

1) Davidson, J (2000), Econometric Theory, Oxford, Blackwell Publishers

2) Edwards, J.R.(1991), Macroeconomics: Equilibrium and Disequilibrium, New York: Macmillan

3) Greene, W.H. (2000), Econometric Analysis, 4th ed., Englewood Cliffs, Prentice Hall

4) IMF, (2001), International Financial Statistics Yearbook, Washington, D.C., International Monetary Fund.

5) IMF, (2001), Direction of Trade Statistics Yearbook, Washington, D.C., International Monetary Fund.

6) Jabber, P. (1986), "Egypt's Crisis", Foreign Affairs, Summer: 7-11.

7) Maddala, G.S. (2000), Introduction to Econometrics, 4th ed. New York, J.Wiley

8) Metwally, M.M., and Rick Tamaschke (1995), "Factors Responsible for Persistent Trade Deficit in Various Developing Countries", Indian Economic Journal, Vol. 43, No.3, Jan-March, PP. 76-91.

9) Metwaly, M.M., and Rick Tamaschke, (1994), "The Foreign Debt Problem of North African Countries", African Review of Money, Finance and Banking, Vol.1, No.2, pp.109-121

10) Metwally, M.M., and Rick Tamaschke (1994), "The Interaction Between Foreign Debt,Capital Flows and Growth: Case Studies", Journal of Policy Modeling, Vol.16, No.6, December, pp. 597-608

11) Metwally, M M and R Tamaschke ( 1980), "Oil Exports and Economic Growth in the Middle East", Kyklos, Vol. 33,Fasc.3.

12) Mittelhammer, R.C., George G Judge and Douglas J.Miller (2000), Econometric Foundations, Cambridge, Cambridge University Press

13) Mukherjee, C., H.White and M. Wuyts: (2000) Econometrics and Data Analysis for Developing Countries: A Time Series Approach, New York, St. Martin's Press. 
14) Thalassinos, E., Pantouvakis, A., Spinalis, A., (2003), "Can Non-expert' Users Analyse Data? A Survey and a Methodological Approach", European Research Studies Journal Vol. VI, Issue 3-4, pp. 109-120.

15) Thalassinos E., Kiriazidis, Th., (2003), "Degrees of Integration in International Portfolio Diversification: Effective Systemic Risk", European Research Studies Journal Vol. VI, Issue 1-2, pp. 111-122.

16) Vernon, R. (1996), "International Investment and International Trade in the Product Cycle" Quarterly Journal of Economics. Vol.80, pp.190-207

17) World Bank (2001), World Tables, Washington D.C., World Bank 